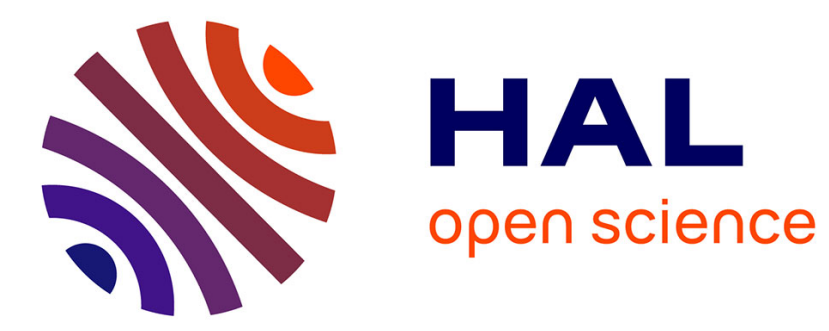

\title{
Towards Sustainable Mobility Indicators: Application to the Lyons Conurbation
}

\author{
Jean-Pierre Nicolas, Pascal Pochet, Hélène Poimboeuf
}

\section{To cite this version:}

Jean-Pierre Nicolas, Pascal Pochet, Hélène Poimboeuf. Towards Sustainable Mobility Indicators: Application to the Lyons Conurbation. Transport Policy, 2003, 10 (3), pp. 197-208. 10.1016/S0967070X(03)00021-0 . halshs-00068232

\section{HAL Id: halshs-00068232 https://shs.hal.science/halshs-00068232}

Submitted on 24 Jul 2006

HAL is a multi-disciplinary open access archive for the deposit and dissemination of scientific research documents, whether they are published or not. The documents may come from teaching and research institutions in France or abroad, or from public or private research centers.
L'archive ouverte pluridisciplinaire HAL, est destinée au dépôt et à la diffusion de documents scientifiques de niveau recherche, publiés ou non, émanant des établissements d'enseignement et de recherche français ou étrangers, des laboratoires publics ou privés. 


\title{
Towards Sustainable Mobility Indicators \\ Application to the Lyons conurbation
}

\author{
J.-P. Nicolas * \\ Laboratoire d'Economie des Transports, ENTPE, rue Maurice Audin, 69518 Vaulx-en-Velin \\ Cedex - France. \\ P. Pochet \\ Laboratoire d'Economie des Transports, ENTPE, rue Maurice Audin, 69518 Vaulx-en-Velin \\ Cedex - France. \\ H. Poimboeuf \\ Association pour les Pratiques du Développement Durable- APDD, 35 rue Ponchardier, \\ BP23, 42009 Saint-Etienne cedex 02 - France. \\ * Corresponding author \\ nicolas@entpe.fr, Tel.: 00334720477 42, fax: 0033472047092
}

\begin{abstract}
This paper applies the theme of sustainable development to the case of urban transport and daily mobility of the inhabitants of a city A set of indicators which simultaneously takes the three dimensions of sustainability -environmental, economic, and social- into account is suggested. We present here the results of an exploratory research funded by Renault Automobile Manufacturers, carried out to verify the feasibility and the usefulness of elaborating such sustainable mobility indicators. Values of the economics, environmental and social indicators are presented for the Lyons case. These estimations are mainly based on the household travel survey held in this city in 1994-1995. In the end, this set of indicators should allow the comparison of different urban transport strategies within an urban area, but also between different urban contexts, and through time. The conditions of generalization of these measurements of indicators are then discussed.
\end{abstract}

Key Words: trip distance; daily mobility; sustainability indicators; household travel survey; methodology; pollutant emissions; expenditures; global costs.

Short Title: Towards Sustainable Mobility Indicators

\section{Introduction}

In its different dimensions, environmental, economic and social, the theme of sustainable development can be regularly found today when the future of urban transport is alluded to. 
On a European level, a framework directive defines a common strategy on air quality assessment and management in member states (OJEC, 1996). At the French level, this directive led to the Law on Air and the Rational Use of Energy December $30^{\text {th }} 1996$, which repeats the European demands for norms in air quality, monitoring and information given to the public as regards air pollution. But, above all, this law offers a planning strategy within which the implementation of "Plans de Déplacements Urbains" (Urban Mobility Plans UMPs) plays a major role in all cities of more than 100,000 inhabitants. It articulates three elements necessary for sustainable development applied to urban mobility. All UMPs must:

- cater to the needs of urban dweller mobility by specifying an efficient transport system;

- allow access to transport service for all;

- offer a better quality of life in cities, notably through better protection of the environment.

This French example is not an isolated case. Most western countries demand that their transport policies conform to sustainable development standards. Assessment tools are gradually being developed to cater to this political will.

These tools sometimes remain centered around environmental issues. For example the TERM project offers a series of annually calculated indicators to follow the evolution of transport related environmental pressure in European countries (EEA, 2000). On a more urban level, the SUTRA project ${ }^{1}$ proposes highly developed insights regarding urban travel impacts on air quality and fuel consumption by combining traffic, atmospheric pollutant emissions and dispersion models.

However integrated approaches simultaneously taking economic, social et environmental dimensions of mobility into account are also appearing (Jones, Lucas, 2000, Kennedy, 2002). This is the case of the "Centre for Sustainable Transportation" in Canada. In this project, the consultation process was emphasized so as to come up with a series of indicators which encompasses the needs of all those involved (Gilbert et al., 2002). In France the RESPECT program is part of the "sustainable cities" network of European cities with an Agenda 21. It also offers a system of indicators aimed at sustainable development in cities with a transport component, even if the area covered is somewhat larger (ARPE Midi Pyrénées, 2001). Other works offer transport policy assessment tools more directly. The PROSPECT European project is a prime example. It compiles a register of conceivable measures and evaluates them (May et al., 2002). It also offers decision making tools to deciders and technicians (Minken et al., 2003).

Compared with these approaches, our work is more that of an analytical approach to the understanding of mobility phenomena and their economic, environmental and social impacts (Nicolas et al., 2001a). These impacts are considered here in terms of "sustainable mobility indicators". The aim is to come up with a tool for sustainability of urban travel systems diagnosis. This is however only possible after a prior study of available data and other information. Such data must be both rich to allow multi level analysis (type of travel, mode, population groups, spatial zoning, etc.) and exist in different urban contexts for comparative analysis. Thus we have begun by using French household travel surveys as a statistical reference base. Only then will work be carried out on other French, then European cities leading to result comparison and analysis.

Below the results for Lyons are presented. Part one consists of the methodology adopted in regard to the indicators. This is followed by a brief presentation of the household travel 
survey and other data used for the calculation. Secondly the approach is shown through a summary of Lyons results.

\section{Methodology}

The objective is to closely analyze the factors related to the sustainability of an urban travel system. This is possible with:

- A system of measurable indicators which show the issues related to sustainable development for urban travel;

- data source which is detailed enough to carry out the analysis and can be found in other urban areas to establish comparisons.

The approach used for the elaboration of the indicators and the use of statistical data is presented below.

\subsection{Which requirements, for which indicators?}

A number of requirements are necessary for effective indicators regarding the objectives here expressed. Notably the indicators must cover the most essential issues at stake, they must have strong coherence with the statistical data base, and they must be simple in the presentation phase that they may be used by all those concerned. Two tables are given which present the indicators chosen (Table 1), the data used to measure them, and indications on the estimation methods (Table 2).

First and foremost, the indicators must take the important issues brought to the fore by urban resident mobility into account. We have thus striven to represent the diversity of inherent problems. However, due to a lack of adapted data we have not developed noise pollution indicators, although noise linked issues are becoming ever more important. Nor have we integrated questions linked to road safety and this for the same reasons.

Furthermore, the issues can be easily seen in terms of economic costs, environmental pressure and social equity. Covering these issues implies that advantages procured by mobility are not to be forgotten. Daily interchanges in the city, economic exchanges, social participation resulting from travel must be considered. These advantages (speed, flexibility, the possibility to reach unconnected places) are to be weighed against quantifiable disadvantages. These are considered below through mobility levels activities carried out, modes used, distances covered and time spent on travelling (Fig. 1). 
Fig. 1: Mobility and its sustainability challenges

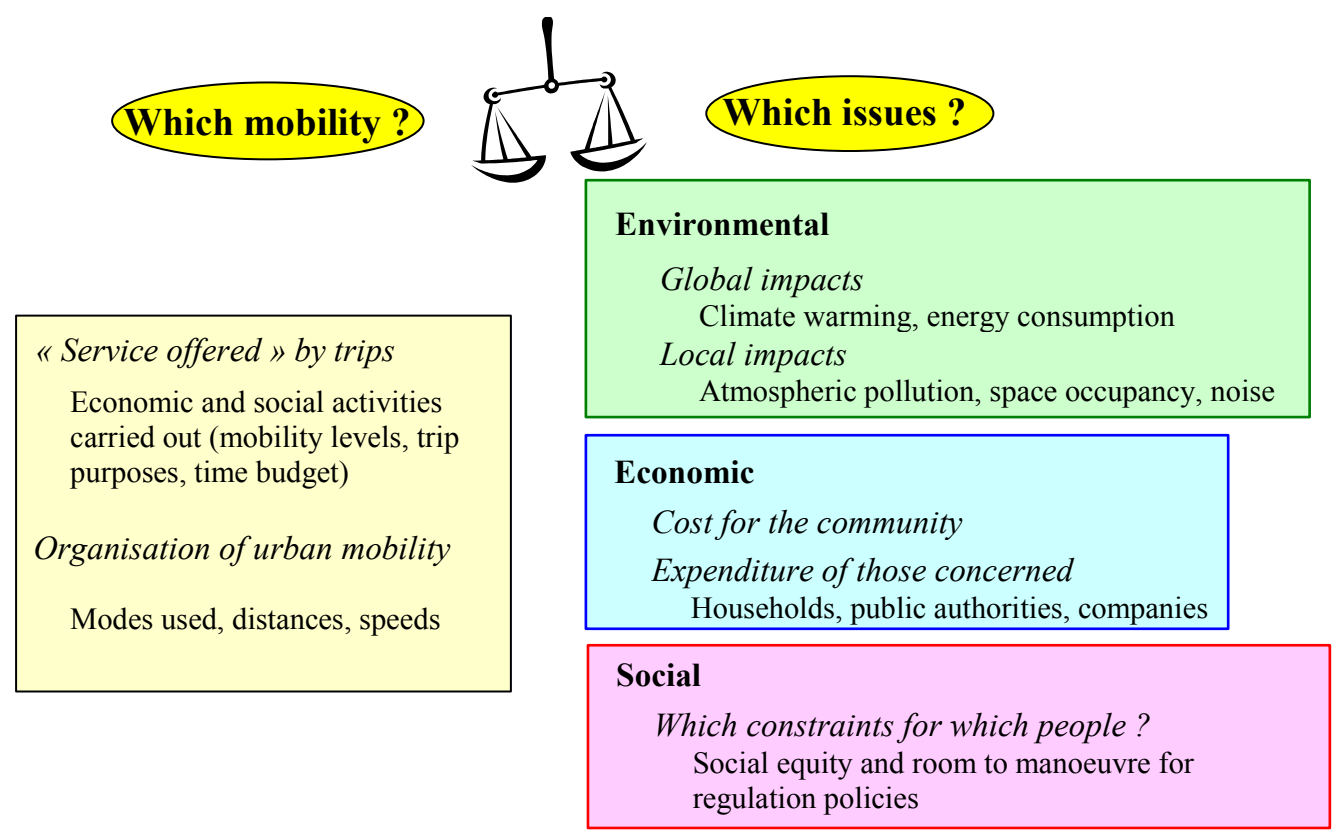

The way to measure these indicators is also of great importance. The most integrated approach possible is used here by calculating the indicators on the same basis as mobility. An example is that of atmospheric pollution as it would have been possible to refer to concentrations of pollutants in the atmosphere. This data is available in most large urban areas and directly corresponds to the issue of air quality. However it does not only depend on inhabitant mobility but also on other activities, climatic conditions, etc. We have preferred to consider the level of emissions calculated from trips found in the household travel survey as an indicator. The values observed by such indicators can be directly explained through analysis carried out on the urban residents in question.

Finally these indicators must give simple, accessible results. The general notion of sustainable development implies wide debate and the democratization of decision making (United Nations, 1992, 2000). This appears even more essential within the framework of the question of sustainable urban mobility, where pollution is caused and suffered by all, to different degrees and in different forms. To facilitate debate and to stretch it beyond the circle of experts technicians and elected representatives, the need for simplicity is obvious, even if it carries a risk of reductionism regarding complex systems.

It must be pointed out that this work of comparison is to be applied to different cities where the spatial configurations, density share, administrative zoning may be very different. To better control this factor we have chosen, where possible, to distinguish the historical dense urban centre, the first ring made up with neighbouring municipalities and the second ring which covers the other municipalities of the studied area. Density measuring of each of these zones allows therefore to observe eventual divergences between compared cities. It is to be noted that this distinction, which is pertinent for European cities, can not be reproduced without caution, for example on North American cities where the notion of "center" may sometimes be vague.

To be transferable to other contexts these indicators need relatively basic information: one (or more) household trip surveys, allowing to know the characteristics of trips on a given day (origins and destinations; modes used; type of car: fuel, age and horsepower, parking) and the characteristics of the household (size and composition, income, location, motorization). Certain elements such as fixed costs may be estimated elsewhere on a semi aggregated basis 
(by category of income, by level of motorization and by place of residence). Also the distances may be estimated from origin and destination. Finally collective costs may be completed by funds given by the community to road networks, public transport as well as diverse contributions from private companies (possible taxes, car parks for employees).

\section{Table 1: Description of indicators used}

\begin{tabular}{|c|c|c|}
\hline $\begin{array}{l}\text { Dimension of } \\
\text { sustainability }\end{array}$ & Indicator & Level of analysis \\
\hline \multicolumn{3}{|l|}{ Mobility } \\
\hline Service provided & $\begin{array}{l}\text { Daily number of trips } \\
\text { Structure of trip purposes } \\
\text { Daily average time budget }\end{array}$ & $\begin{array}{l}\text { Overall \& by place of residence } \\
\left(\text { Centre } / 1^{\text {st }} \text { ring } / 2^{\mathrm{d}} \text { ring }\right)\end{array}$ \\
\hline $\begin{array}{l}\text { Organization } \\
\text { of urban mobility }\end{array}$ & $\begin{array}{l}\text { Modal split } \\
\text { Daily average distance travelled } \\
\text { Average speed } \\
\quad \text { (global and per person) }\end{array}$ & $\begin{array}{l}\text { Overall } \\
\text { \& by mode of transport }\end{array}$ \\
\hline
\end{tabular}

\section{Economic}

Cost for the community

Annual costs chargeable to residents of the conurbation, due to their mobility in this zone (total ${ }^{\mathrm{a}}$, per resident and per passenger-km)

Expenditures of the participants involved

\section{Households:}

Annual average expenditures for their urban mobility (per person)

\section{Companies:}

Costs of employee parking

Subsidies to employees (company cars...) Overall $\&$ by mode

Possible local taxes

(total, per resident and per employee)

Public Authorities:

Annual expenditures for investments and operates (total and per resident)

Social
Proportion of households owning 0,1
or more cars
Distance travelled
Expenditures for urban mobility:
- amounts for private/public transport; for
fixed/variable cost of car
- share of the average income of households

\section{Environmental}

Air pollution -

Global issue

Annual energy consumption and $\mathrm{CO}_{2}$ emissions (total and per resident)

Air pollution -

Local issue

Levels of CO, NOx, hydrocarbons and particles (in $\mathrm{g} / \mathrm{m}^{2}$, total and per resident)

Space consumption

Other items

Daily individual consumption of public space involved in travelling and parking (in $\mathrm{m}^{2} . \mathrm{h}$ ) Space taken up by transport infrastructures

Noise intensity levels

Risk of accident

${ }^{\text {a }}$ Before taxes, to avoid double accounts.

${ }^{b}$ The expression of population densities in each of these zones will make the comparison of the results of different conurbations easier.

${ }^{c}$ Not measured in our case study, due to lack of data.
Overall \& by mode (Car, Public Transport, Other)

Overall \& by mode

Overall \& by mode (Road / Public Transport)

Overall, by income group

(Low, medium, high)

$\&$ place of residence

(Centre / $1^{\text {st }}$ ring / $2^{\text {d }}$ ring)
Overall, by mode, by zone of emission, by place of residence

Overall, by mode, by zone of emission, by place of residence ${ }^{b}$

Overall, by mode and by place of residence

Overall \& by place of residence 
Table 2. Data sources and method of measurement

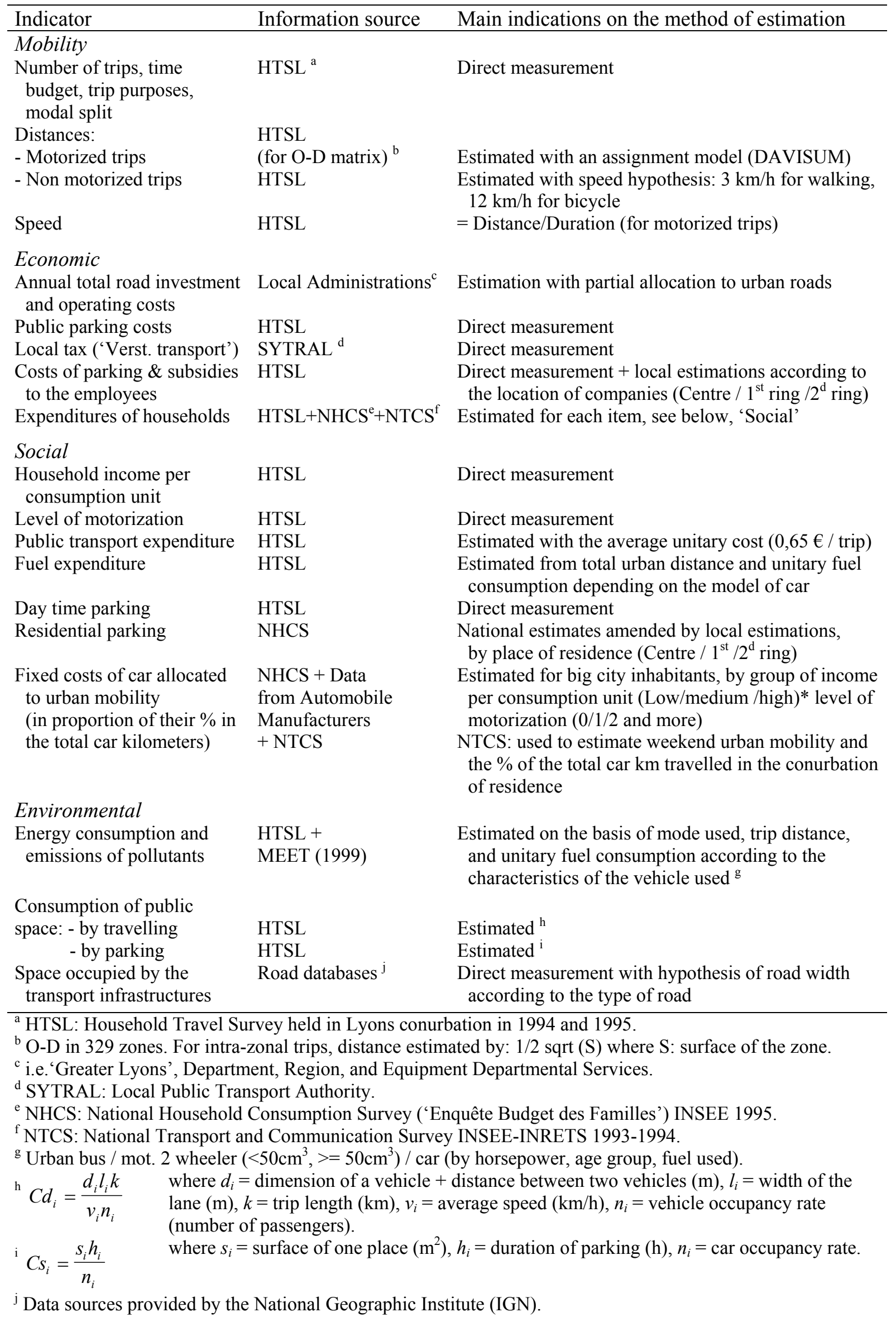




\subsection{The household trip surveys and the other information sources}

This set of requirements has led us to consider the use of household trip surveys as a good data source. The information furnished by such surveys is extremely rich. The basic statistical item is the trip, shown through the mode, its origin, its destination etc. For each trip we can thus piece together its environmental impact and its cost - which is what we have done here. These surveys also give a description of the persons who carried out these trips, their socialeconomic characteristics and their reasons: social indicators can therefore be built from such surveys. This richness also leads to numerous investigations to understand the socialeconomic dynamics of the observed trip system and to describe their impacts. Analysis can therefore be made on a trip level or on a more aggregated level by mode or population type, depending on what is needed. These advantages were used by Jean-Pierre Orfeuil to put forward the idea of Transport Energy Budgets (Orfeuil, 1984), subsequently widened to Trip Environment Energy Budgets (see for example Gallez, 1995).

Inquiries of this type have been carried out in most European cities. Different methodologies exist from country to country, but even if they need specific treatment, the scope for comparison is real.

On a French level the household trip surveys which were used in our work follow a standard nation-wide procedure, assuring easy reproducibility for the proposed indicators. The survey is supervised by the CERTU ${ }^{2}$ (CERTU, 1998). Locally renewed every 10 years or so in all large French cities, these surveys take all people over the age of 5 years belonging to surveyed households, who are representative of the perimeter under study, into consideration. They record socio-economic characteristics together with all trips carried out on the day before the survey. In the Lyons case, in 1995 we have thus information concerning 6000 households, i.e. 14000 individuals who carried out 53000 trips.

The advantages of these surveys must not however mask their limits. They were not made with a view to studying sustainable development, and a certain number of estimates from other sources are necessary. Their limits depend on the specific method chosen for each country. In this paper we will content ourselves here with those met in France.

1/ First, information furnished by the survey must be completed in various ways depending on the indicators to be elaborated. For example, the French surveys offer no indication as to the generation of a trip's environmental pollution, and very little information allowing the calculation of costs. Therefore other data bases were consulted notably for pollution emissions (MEET, 1999) and, for household automobile fixed costs.

2/ Furthermore French household trip surveys give only the origin and destination of each trip, without precision regarding the itinerary. In the Lyons case we have used an assignment model for motorized trips, which represents the majority of distances covered $(94 \%$ of passengers*kilometers by our calculations). Sensitivity tests show however that the use of "as the crow flies" distances between origins and destinations corrected by a factor of 1.3 gives very satisfying results on a more aggregated level ${ }^{3}$.

3/ Finally this kind of survey records only the daily trips of those residing within a given perimeter. Transit traffic, peri-urban residents coming into the city and goods traffic in the city area are not covered. In our case, by blending with results from traffic models of different natures taking place in the Lyons urban area (Routhier, Ambrosini, 2001; Durand, Masson, 2001), they were estimated to represent some $45 \%$ of total vehicles*kilometers expressed in $\mathrm{PCU}^{4}$ covered in the whole of the city of Lyons. At rush hours, according to estimations from Lyons CETE (Centre d'Etude Technique de l'Equipement - Equipment Technical Studies 
Center), this portion, as yet not taken into account, reaches $51 \%$ due to the significant distances covered within the perimeter by peri-urban residents working in the conurbation.

Fig. 2. Urban traffic not considered in the household trip surveys

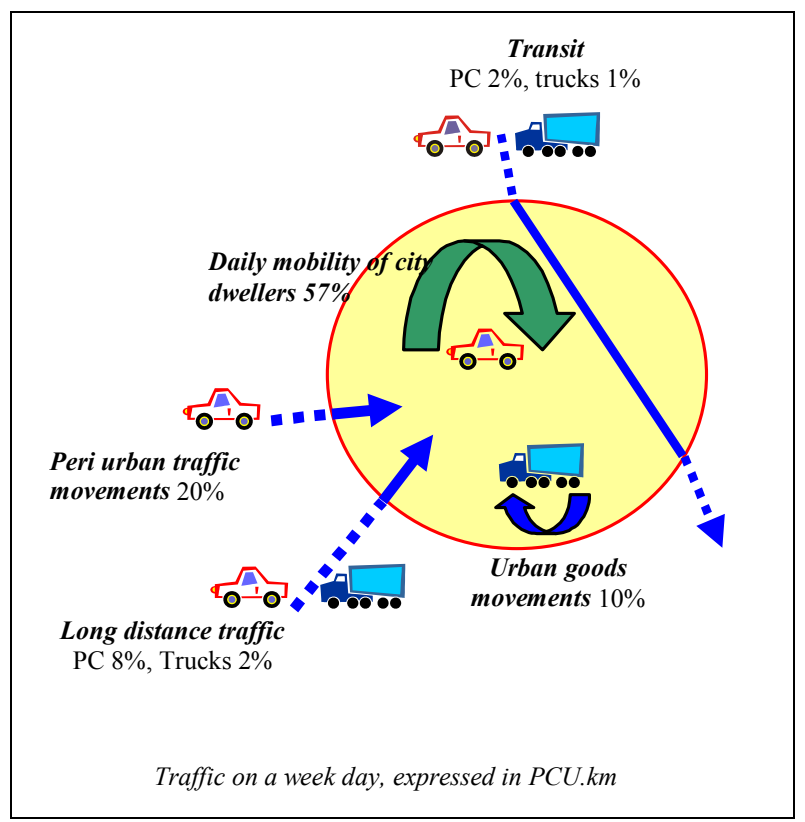

These trips, both for people and goods, which do not come within the sphere of our field of study, are not subjected to the same economic or social logic and their regulation does not involve the same tools as the mobility that we have focussed on: the daily mobility of city dwellers in urban areas. It must be underlined for exercises of comparison that their importance depends on the size of the perimeter surveyed. In particular, the larger the perimeter is, the more peri-urban traffic is considered inside the study area. To compare two urban areas correctly, it is thus important to estimate the different types of trips not taken into account. The distinction between centre, $1^{\text {st }}$ and $2^{\text {nd }}$ ring also makes the comparison between various perimeters easier.

\section{Which urban mobility for which results?}

\subsection{Lyons inhabitant mobility through the household trip survey of 1994-1995}

Greater Lyons, as shown in the household trip survey of 1995, counts 1.2 million inhabitants for $1,100 \mathrm{~km}^{2}$. The population is highly concentrated within a dense urban centre: $45 \%$ of the population residing on $5,7 \%$ of the territory, resulting in a density of 8900 inhab/ $\mathrm{km}^{2}$ as opposed to 430 in the $2^{\text {nd }}$ ring. This perimeter is smaller than that of the INSEE urban area, which better represents the Lyons zone of influence.

These differences are clearly visible in the mobility of city dwellers. From one zone to another, trip systems are easily seen to change with density and dwelling type. Mobility measured in number of trips appears identical: 3.7 trips per person on average. On the other hand while walking, public transport and the car are used in a relatively balanced way in the centre $(1.59 ; 0.63$ and 1.57 daily trips respectively), the car quickly takes the lead in less dense areas $(0.73 ; 0.30$ and 2.50 daily trips). Daily distances per inhabitant constitute the determining indicator for pollutant emissions. They are much longer in peripheral areas (Fig. 3) as they are covered more quickly thanks to the car. In this way, time given over to 
travelling remains more or less the same throughout the city (59 minutes on average by day and by person).

Fig. 3. Daily distances covered by mode according to the place of residence

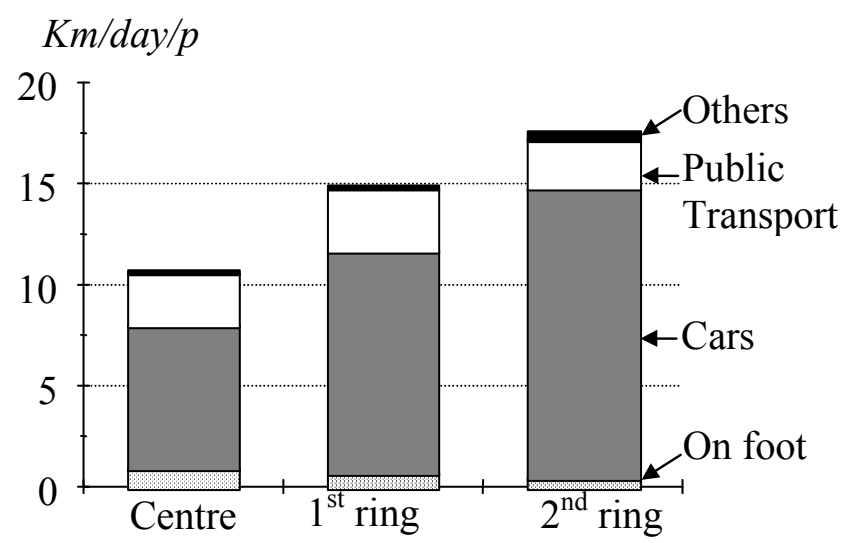

The urban context, and notably the size of the city, play a determining role which may appreciably effect the proposed indicators of sustainable mobility. Thus a comparison with the Paris region which counts 10 million inhabitants (in a larger study area than Lyons as it covers the whole of the Ile-de-France region, Gallez, 1995) shows simultaneously:

- strong similarities in the number of trips per day per person and in the structure of purposes,

- but also notable differences:

* regarding distances covered, whether the place of residence is central or peripheral (on average $+70 \%$ in the Parisian region),

* high use of public transport in Paris (12.1 km per day per person in privately owned cars and 10.0 in public transport, against 10.4 and 2.6 in Lyons),

* and in higher speeds in Paris $(17.4 \mathrm{~km} / \mathrm{h}$, all modes together, against 14.1 in Lyons).

However, despite a more efficient transport system in Paris, a Parisian daily spends $30 \%$ more time on trips than his Lyons counterpart. The study area definitions explain these differences to a certain degree: unlike the household trip survey which was carried out throughout the Ilede-France, in Lyons it did not include the whole inhabited area basin: taking Lyons and its surrounding area into account would result in an additional population of $20 \%$, and with an increase in total distances to the order of $30 \%$ on the total. Average distances would thus be affected, but the differences in scale between the two examples would be such that the major divergence in terms of distance and time budget would remain.

Thus, even if they cater to the same type of needs, the transport systems of the two cities could be organized differently and would seemingly have markedly divergent environmental, economic and social impacts.

Beyond the service supplied by the trip system thus presented (level of mobility and trip purposes) and by its organizational characteristics (modes used, distances covered, daily trips speeds and lengths), questions remain to be asked concerning its functioning and its environmental impacts. 


\subsection{Economic indicators: global costs of the Lyons urban transport system}

From an economic standpoint, the aim is to determine the cost-efficiency of travel within the conurbation by a close analysis of its global cost on one hand, and the cost per mode of travel on the other hand. The idea is to draw inspiration from French "trip accounts" (Duprez, 2001), by identifying " who pays for what » and by overlapping the different points of view: that of the community as a whole first, and also that of the different participants involved: households, companies and public authorities. Costs and constraints felt by those participants do not necessarily fit this first picture due to State managed fiscal transfers of all sorts. It should be noted that the environmental pollution, such as atmospheric pollution and public space occupancy, although they have been physically measured, have not been taken into account economically. We endeavored to avoid the same element being taken into account twice, in the environmental sphere and in the economic sphere. We also wanted to clearly distinguish, from an analytical standpoint, what belongs to each of these two dimensions.

The household trip survey alone is not sufficient to estimate the costs and economic efficiency of a conurbation travel system. Other sources of information are thus necessary (Table 2).

First, as regards the travelling of individuals, it is essential to estimate fixed car costs. This has been accomplished thanks to the National Household Consumption Survey of 1995. Only a part of these fixed costs should be allocated to urban mobility. For that goal, keys to sharing of mobility between "urban" and "interurban" areas are needed_(Nicolas et al., 2001b). We used the National Transport and Communication Survey to estimate, firstly, the share of urban kilometers covered during the weekend and, secondly, the proportion of own-city kilometers covered.

Furthermore, the budgets committed by the other participants (firms, local authorities, the State) are not, by definition, covered by these surveys. Since "trip accounts" do not yet exist in the Lyons conurbation, the different authorities involved enabled us to reconstitute this information.

Urban trips carried out by the inhabitants of Lyons carry a total overall cost of 1.15 billion euros 2002, before tax and for all participants (households, public authorities and companies). This corresponds to an average collective cost of 955 euros per person and per year, made up of 670 for the automobile (69\% for vehicles and their running, $21 \%$ for parking fees, $10 \%$ for roads), 260 for urban public transport and 25 for the other modes (Fig. 4).

\section{Fig. 4. Cost components for urban mobility: the collective viewpoint}

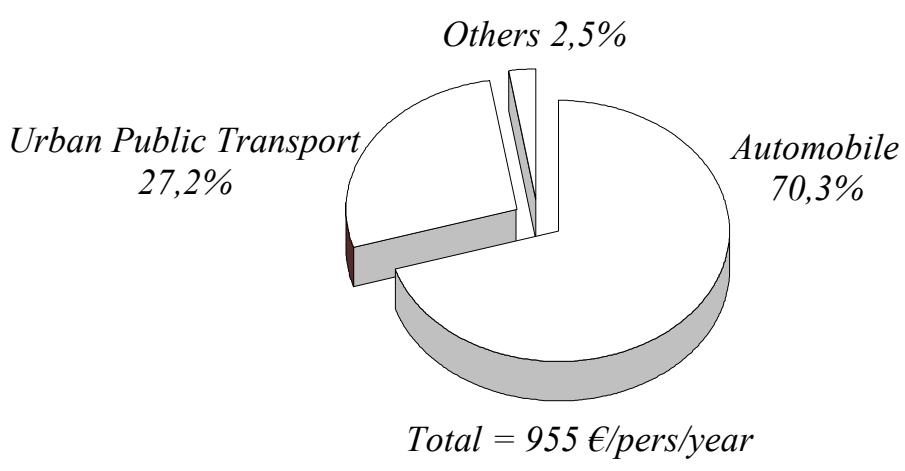

Considering the organization of different transport modes, and their respective costs and the frequency of their use by the inhabitants of Lyons, this corresponds to a total average cost of 0.23 euros per passenger-kilometer. Wide variations appear by mode $(0.21$ euros per passenger-kilometer in cars, 0.46 for urban public transport, 0.23 for other public transport, 
0.37 euros for motorized two wheels and a cost considered as nil for the other modes). These differences should be interpreted with caution for, taken in isolation from the other dimensions, they do not take service supplied by each mode into consideration. For example public transport allows good car traffic flow in the centre and fills a role of public service, notably for the "non-motorized". These figures help to remind us that if an alternative to the car policy is to be offered by the development of public transport, it carries non negligible costs.

Because of State run transfers, these costs are not uniformly felt by the different participants. All taxes included, households therefore spend 835 euros per person per year on the car and 75 euros on public transport (all households together, with or without a car, on their urban mobility within the city). Companies pay 510 euros tax per year and per job, or 130 euros per inhabitant (this tax, called "versement transport", partially finances public transport investments). They also pay an annual equivalent of 83 euros per employee for parking and approximately 70 euros for their mobility (company cars). As for the State, it consecrates 76 euros per person per year for roads and parking, and 70 euros per person per year for public transport.

Let it be underlined that the set of figures presented here appear to be sound. Calculated household expenditure tie up with SYTRAL accounts regarding public transport, and national evaluations of overall automobile mobility (on average 4,415 euros per household in Lyons in 1995, against, respectively, 4,100 and 4,570 euros on a country-wide level for the national accounts and for the automobile manufacturers). These averages hide important disparities depending on household size, their income and their location within the city.

\subsection{Social indicators: distances covered unaffected by income, but highly variable budget constraints}

In a context of increasing income inequalities in France as in most OECD countries (Piketty, 1997), and of marked sensitivity of city-dwellers to the evolution in their daily mobility costs, the social equity issues should be examined very carefully. What urban distances do they cover, for which purposes, and how much of their budget do the expenditures for their daily mobility represent? In order to consider the relative constraints and positions within the urban population, it is necessary to relate the various indicators (distance travelled, expenditures) both to the level of income ${ }^{5}$ and to the place of residence.

We have seen that French household trip surveys do not provide any information on expenditure. This expenditure therefore had to be estimated in different ways according to the following items: for fuel expenditure, on the basis of the mileage done, for daytime parking, on the basis of the number of trips as driver of a car using paying parking facilities. The Household Consumption Survey, supplemented by data from automobile manufacturers, enabled us to work out the fixed automobile costs (purchase, repair and maintenance, insurance, road tax) according to different categories of income*motorization. Lastly, a value was estimated for the parking costs in terms of the place of residence and the number of cars owned by the household. This figure was entirely attributed to urban use (Table 2).

The first results obtained indicate that the car is by no means a fully democratized good (Fig. 5). Among low-income households, $40 \%$ do not have a car, as against less than $25 \%$ in average income households and less than $10 \%$ in high income households. Furthermore, in Lyons as on the national level, multiple car-ownership occurs essentially in high income households (Hivert, 2000). 
Fig. 5. Rate of individual car-ownership in households according to their category of income per consumption unit

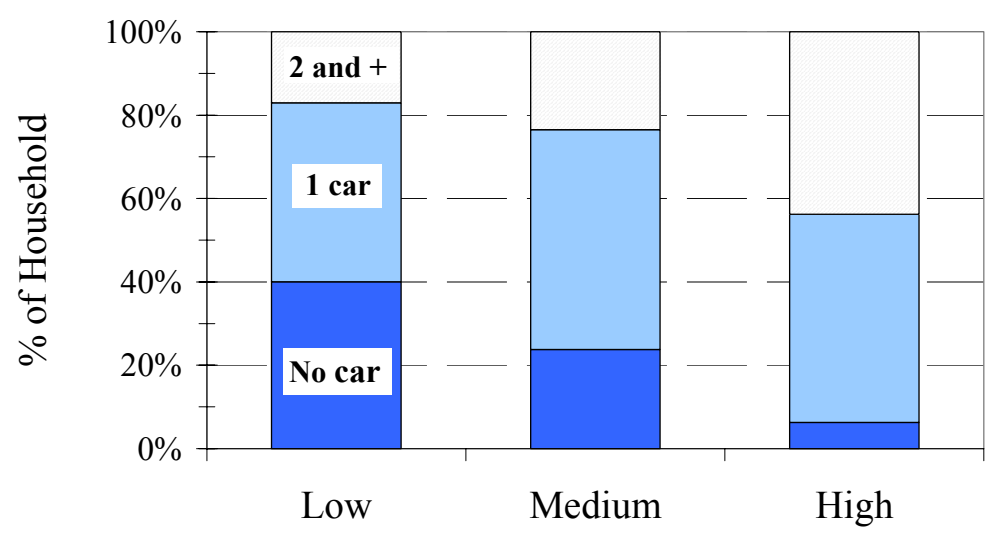

Group of Income per Consumption Unit

Car-ownership, however, is sufficiently widespread so that even among low-income households, more than $2 / 3$ of couples in which neither of the spouses works, own a car, as do $85 \%$ of childless couples and $90 \%$ of families with at least one working member. This widespread private car-ownership and the growing use of the car has generated considerable private costs for certain household categories, placing the issue of social equity at the centre of the debate on urban transport.

Ten per cent of urban dwellers, mostly working individuals, suburban residents, account for $40 \%$ of the total distances travelled. On the whole, this analysis confirms that the size of the household and its structure greatly determine the activities and the trips to be made, as well as the daily distances covered, this last indicator being closely linked to the place of residence. It is worth noting that, all other things being equal, economies of scale have little impact on the organization of mobility: non-working couples cover approximately twice the mileage of single non-workers; the same applies to childless working couples compared to single working individuals. The comparison of distances covered by families and couples with only one wage-earner indicates that the presence of children in the home increases the mobility needs of the home unit well beyond the trips made by the children themselves. However, for a given economic status and place of residence, the distances covered hardly vary. If income does play a crucial role, its influence occurs well before, in the choice of place of residence, in the possibilities of motorization (especially bi-motorization) and the kind of car used ${ }^{6}$. Its influence is also situated downstream, in the expenditure linked to urban mobility.

The amount spent per household is thus closely dependent on income and place of residence, from just under 100 euros per month for low-income inner-city households, to approximately 330 for high-income suburban households (Fig. 6). However, due to significant income disparities, the efforts made by households to meet the requirements of urban mobility, measured in income share, provides a totally different ranking, from 6 to $12 \%$ between the high-income urban dwellers and the low income households of the $2^{\text {nd }}$ ring, these rates increasing to beyond $15 \%$ for motorized households of this latter group.

Another interesting result that the expenditure indicators outline, in low-income households, is that the structure of expenditure is slightly more affected by variable costs, in public transport (20\% of the total, as opposed to less than $10 \%$ in other households) and in fuel $(24 \%$ of the car budget as opposed to 20\%). This greater share of variable costs in the "urban transport budget" of the less privileged households can be attributed to more frequent use of 
public transport and also to the more frequent purchasing of second-hand vehicles although the use of each of these vehicles is as important for them as it is for privileged households.

\section{Fig. 6. Amounts and share of average income dedicated to urban transport by households, according to income and place of residence}

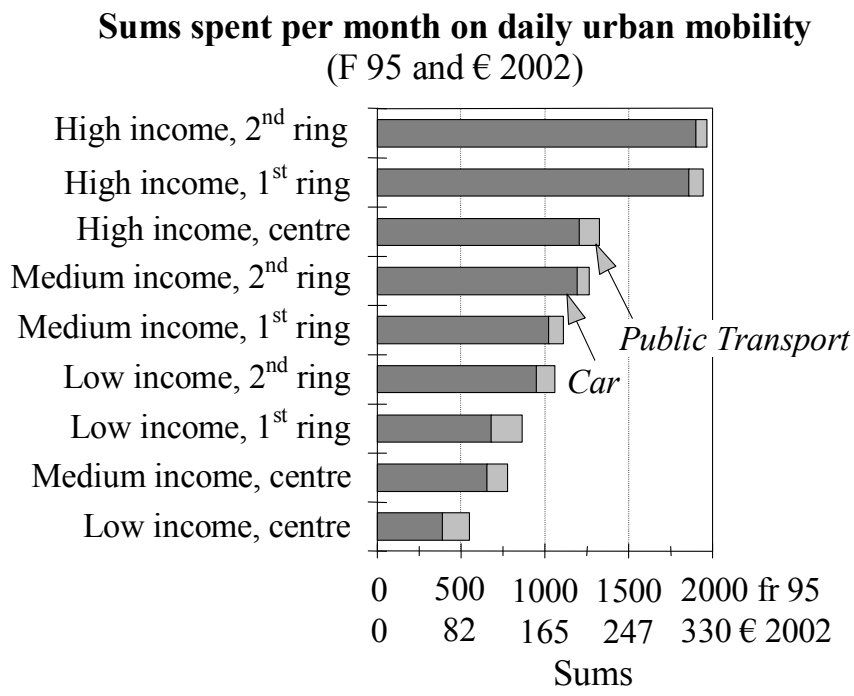

$\%$ of average income

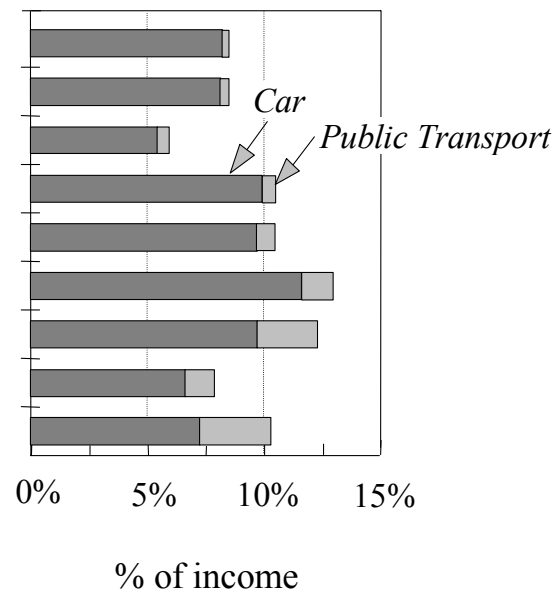

This higher share of income dedicated to urban mobility, strengthened by a greater impact of the variable costs in the overall total, highlights how extremely sensitive less privileged households are to any variation in the running cost of the car. This was shown by the sudden increases in fuel costs in the year 2000, especially (although not only) in the case of suburban households who tend to use their car(s) frequently. The same reasoning applies, to a lesser degree, to public transport costs, especially in the case of low-income households in the city centre or the first ring.

\subsection{Environmental indicators: urban vs. suburban?}

The gap between transport and the environment seems to grow each day more:

- on a global level, from the two oil crises of the $70 \mathrm{~s}$ and the awareness of energy consumption to now, with greenhouse concerns;

- on a local level, with the growing anxiety regarding atmospheric pollution, the increase in noise pollution, the more visible physical presence with rising automobile mobility and the development of road infrastructures.

Within this framework, three sets of issues were retained to treat the environment question: those of global greenhouse effect and energy consumption; local issues of local atmospheric pollution (noise pollution should also be integrated, but could not be so due to the difficulty of bringing simple pertinent indicators to light); issues in terms of the space taken up by road infrastructures and by the different modes.

Regarding the levels of pollutants emitted per mode, our calculations have given rise to a certain number of results (Table 3):

- The car, including driver and passengers, which represents $53 \%$ of trips and $74 \%$ of the distances covered in the conurbation, is ranked first as being responsible for almost all $\mathrm{CO}$ and hydrocarbon emissions, more than $90 \%$ of the $\mathrm{CO}_{2}$ emissions and fuel consumption, more than $80 \%$ of the NOx emissions and particles. 
- Public transport which accounts for $13 \%$ of trips and $19 \%$ of all distances covered, does contribute to NOx (19.5\%) and particles (15\%) due to diesel engines. The impact of public transport is relatively limited because of the subway system which emits nothing and accounts for $35 \%$ of the passengers-kilometer of the network, and because of its rate of occupancy: the essential stakes are laid here for public transport systems, i.e. these two variables of occupancy and the proportion of electric traction.

It is worth mentioning that motorized 2-wheeled vehicles emit 6 times more hydrocarbons than the proportion of mileage covered - even if their numbers are still relatively low.

Table 3. Role of different modes in trips and emissions of pollutants in the Lyons conurbation

\begin{tabular}{|c|c|c|c|c|c|c|c|}
\hline & \multirow[t]{2}{*}{$\%$ of urban trips } & \multirow[t]{2}{*}{$\%$ of distances } & \multicolumn{5}{|c|}{$\%$ of emissions of pollutants } \\
\hline & & & $\mathrm{CO}_{2}$ & $\mathrm{CO}$ & VOC & NOx & Particles \\
\hline Car passenger & 12,3 & 15,1 & - & - & - & - & - \\
\hline Car driver & 40,7 & 58,9 & 91,8 & 98,4 & 94,7 & 80,3 & 84,7 \\
\hline Essence vehicles & 29,2 & 40,2 & 60,7 & 96,7 & 91,4 & 64,9 & 0,0 \\
\hline Diesel vehicles & 11,5 & 18,7 & 31,1 & 1,7 & 3,3 & 15,5 & 84,7 \\
\hline Urban public transport & 12,2 & 16,8 & 6,9 & 0,7 & 1,3 & 17,3 & 12,9 \\
\hline Non urban public transport & 1,1 & 2,3 & 1,1 & 0,1 & 0,3 & 2,2 & 2,2 \\
\hline Motorized 2-wheeled vehicles & 0,6 & 0,6 & 0,1 & 0,9 & 3,7 & 0,0 & 0,0 \\
\hline Walk & 32,0 & 5,2 & 0 & 0 & 0 & 0 & 0 \\
\hline Bicycle & 0,7 & 0,6 & 0 & 0 & 0 & 0 & 0 \\
\hline Other modes & 0,4 & 0,5 & 0 & 0 & 0 & 0 & 0 \\
\hline Total & 100,0 & 100,0 & 100,0 & 100,0 & 100,0 & 100,0 & 100,0 \\
\hline
\end{tabular}

In order to better highlight local problems, these initial comments need to be refined by a more geographical approach, which will give an overview of concentrations according to the zone of emission. The pollutants were therefore attributed to their place of emission on the basis of the trip which generated them; this enabled us to estimate rates of emission per $\mathrm{m}^{2}$ within the city centre, the first and second rings.

The results obtained emphasize the importance of the type of urbanization, and especially of the density of places of residence on the emission levels of pollutants. The car is the most frequently used mode of transport and also the most polluting for a kilometer covered; variations in its use can explain the very different levels of emission linked to places of residence. Indeed, the dispersion of activities in the suburban zones increases the length of trips and local residents need more space in which to drive around. They emit 2.5 times more atmospheric pollutants than city centre residents, thus contributing significantly more to regional and world pollution (Fig. 8).

The context in the city centre is different. Human and activity concentration lead to a considerable concentration of emissions; this zone of urban space is thus much more sensitive to local pollution. The level of emission per $\mathrm{m}^{2}$ is, for instance, 15 times higher than in suburban areas, and is directly related to the concentration of car traffic (Fig. 7). 
Fig. 7. Emission rates per $\mathrm{m}^{2}$ depending on the zone

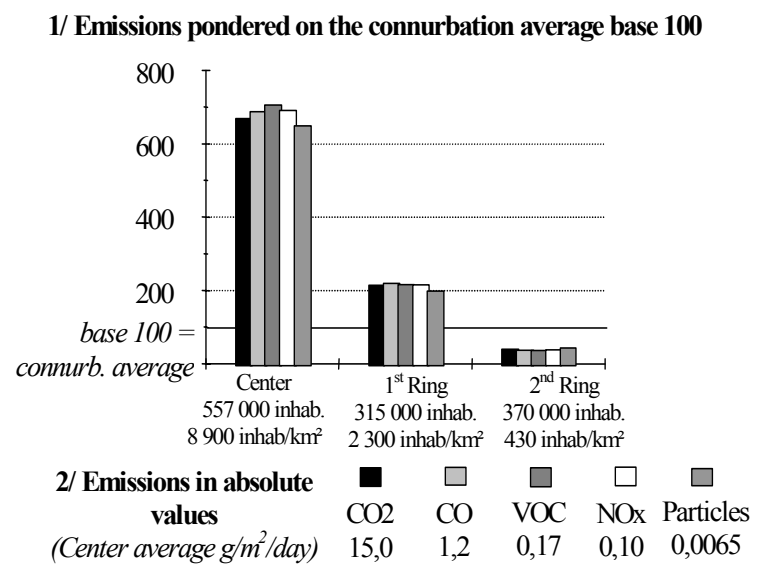

Fig. 8. Emission levels per person and per day depending on place of residence

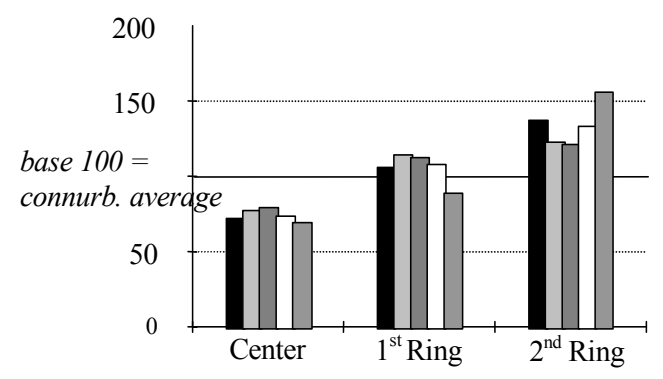

On the one hand we have a dense city centre concentrating traffic flows and populations which have a significant negative impact on the immediately and locally perceived sources of pollution; on the other hand we have sprawling suburban zones where emissions of pollutants are less perceptible since they are diluted over larger areas. In these suburban zones, the problems of space occupancy, and of regional and global pollution are likely to increase as a result of the expected growth of traffic.

In terms of space occupancy, differences linked to the place of residence may be noted. Hypotheses of mobility time*space consumption and of parking space consumption of the different modes of transport (Vivier, 1997 or see Table 2), enable us to analyze the space taken up by the inhabitants of Lyons to move according to their place of residence and their chosen mode of transport. It has been chosen to focus this measurement on public space occupancy (Table 4) for the use made by individuals of their private space has already been valued in the economic and in the social dimensions (Table 2).

Table 4. Daily individual consumption of public space taken up by travelling according to the place of residence in the Lyons conurbation (in $\mathrm{m}^{2} . \mathrm{h}$ )

\begin{tabular}{ccccccc} 
& \multicolumn{2}{c}{$\begin{array}{c}\text { Automobile } \\
\text { Travel }\end{array}$} & $\begin{array}{c}\text { Public } \\
\text { Pransport } \\
\text { Travel }\end{array}$ & $\begin{array}{c}\text { Walk }+ \\
\text { bicycle } \\
\text { Travel + parking }\end{array}$ & $\begin{array}{c}\text { Motorised } \\
\text { 2-wheeler }\end{array}$ & Total \\
\hline Centre & 10,7 & 31,7 & 0,83 & 0,53 & 0,28 & 44,0 \\
$1^{\text {st }}$ ring & 15,6 & 27,9 & 1,45 & 0,44 & 0,24 & 45,6 \\
$2^{\text {d }}$ ring & 22,5 & 21,6 & 0,98 & 0,50 & 0,43 & 46,0 \\
\hline All together & 15,4 & 27,8 & 1,03 & 0,50 & 0,32 & 45,0 \\
\hline
\end{tabular}

Public space taken up daily by individual travelling is relatively unaffected by the place of residence: approximately $45 \mathrm{~m}^{2} . \mathrm{h}$ per person and per day. Additional stable data is that the car accounts for most of the consumption of public space (on average 96\%) regardless of the place of residence. Parking seems to be an essential component of this consumption of space. Indeed, even if a moving car takes up more space than a stationary car, it is moving less than $5 \%$ of the time $(4.7 \%$ according to the Lyons household trip survey). Although private parking lots is the favored option in the Lyons conurbation, a car is parked on average 7 hours in public spaces, totaling $31 \%$ of the overall parking time. Space occupancy linked to modes of transport thus highlights clear differences related to proximity to the city centre. 
Within the conurbation, for each $\mathrm{m}^{2}$ taken up by travelling, 30 are taken up by the infrastructures. This high rate varies according to zones: 1 to 11 for the city centre, 1 to 22 for the $1^{\text {st }}$ ring and 1 to 65 for the $2^{\text {nd }}$ ring. Even if estimates were made at the time of construction, these figures are clear reminders that sprawling suburban housing is a greater consumer of space than city centre housing.

\section{Conclusion and further research}

The objective has been reached: it is possible to develop indicators of urban mobility from an angle of sustainable development. The application carried out on the Lyons case shows that consistent results can be obtained with the possibility of close analysis within each dimension, economic, social and environmental. Using household travel surveys results in strong coherence between the analysis carried out in the three fields.

The next step to be taken is to reproduce this approach on a number of urban areas with differentiated characteristics, as much their size and the organization of their transport system as their urban structure. These contexts can differ greatly from city to city, as can be supposed from the comparison of mobility in the Lyons urban area and the Paris region. The highlighting of these differences will nourish thought on the sustainable character of urban travel systems. These comparative analysis will also lead to refining the non exhaustive list of indicators proposed here.

As the data sources are homogeneous for France, a comparative analysis is ongoing. It also appears to be very interesting to explore statistical resources in different European countries to lead an international comparison with different mobility cultures and contrasted urban policies.

A second direction concerns the possibility of integrating such indicators in forecast tools. Given the present day developments of issues linked to mobility, it seems useful to have a strategic model to throw economic, social and environmental light on the different scenarii for urban travel system developments to be tested. Previous comparison studies on different urban areas would help in selecting the more pertinent indicators.

Finally, the more descriptive and analytical, as opposed to normative, approach proposed in the article must be insisted upon. Our aim is not to offer norms to define sustainability and our definition of the notion of sustainable development remains relatively loose. Two principles linked to that notion guided this work. First of all, it has become more and more urgent to be able to consider mobility and its different dimensions in an integrated fashion instead of systematically looking at only one of them at a time. Furthermore, and this remains within the logic of the preceding point, the aggregation of different indicators does not seem to be a good approach. Economics, social and environmental fields are partly irreducible one from the other. The tool proposed here is not to offer a hierarchy of situations and projects which could be compared. Our objective, upstream, is to widen points of view to fuel debate. Necessities for sustainable development can be found more on the idea that the conditions of development of a transport system join those of a paretian process regarding the different dimensions envisaged. Between the service rendered by urban mobility, its environmental impacts, its costs and the questions of social equity which arise, all recorded improvement within one dimension could be interpreted positively as long as it is not to the detriment of another. 


\section{References}

ARPE Midi Pyrénées (2001) 'Diagnostic développement durable urbain, tome 2, Les indicateurs'. http://www.respect.asso.fr

CERTU (1998) Enquête ménages déplacements, méthode standard. Ed. CERTU, Lyons.

Commission of the European Communities (1995) 'Green paper towards fair and efficient pricing in transport policy options for internalizing the external cost of transport in the European Union'. Direction General for Transport, Brussels.

Duprez, F. (2001) 'Local Transport Accounts: Improving Knowledge on Transport Costs'. Working Paper. Fabien.Duprez@equipement.gouv.fr.

Durand, S., Masson, S. (2001) 'TELESCOPAGE: multi-scale combining model of simulation in a conurbation'. Paper presented at the 9th World Conference on Transport Research, Seoul, July 2001.

European Environmental Agency (2000) 'Are we moving in the right direction - Indicators on transport and environment integration in the EU'. http://www.eea.eu.int.

Gallez, C. (1995) 'Budgets énergie environnement des déplacements (BEED) en Ile-de-France'. ADEME-INRETS, Paris.

Gallez, C. (2000) 'Indicateurs d'évaluation de scénarios d'évolution de la mobilité urbaine'. DTTINRETS, Paris.

Gilbert, R. et al. (2002) 'Sustainable transportation performance indicators' (STPI) Projects, reports on phase 3. CSTCTD. http://www.cstctd.org/CSTcurrentprojects.htm

Hivert, L. (2000) 'Inégalités d'accès à l'automobile'. ADEME-INRETS, Paris.

Hourriez, J.-M., Olier, L. (1997) 'Niveau de vie et taille du ménage : estimations d'une échelle d'équivalence', Economie et Statistique, 308, pp. 65-94.

Jones, P., Lucas, K. (2000) 'Integrating transport into 'joined up' policy appraisal', Transport Policy, 7 (3), pp. 185-193.

Kennedy, C. A. (2002) 'A comparison of the sustainability of public and private transportation systems: Study of the Greater Toronto Area', Transportation, 29, pp. 459-493.

May, T., et al. (2002) 'KONSULT - Knowledgebase on Sustainable Urban Land Use and Transport'. http://www.transportconnect.net/konsult/

MEET Project (1999) Methodology for calculating transport emissions and energy consumption. Office for Official Publications of the European Communities, Luxembourg.

Minken, H., et al. (2003) 'Developing urban land use and transport strategies, a methodological guidebook'. European Commission, $5^{\text {th }}$ framework - EESD. http://www.ivv.tuwien.ac.at/projects/prospects/Deliverables/pr_del14mg.pdf

Nicolas, J.-P., Pochet, P., Poimboeuf, H. (2001a) 'Indicateurs de mobilité durable sur l'agglomération lyonnaise'. Etudes \& Recherches 16, LET, Lyons.

Nicolas, J.-P., Pochet, P., Poimboeuf, H. (2001b) 'Construction et évaluation d'indicateurs de mobilité durable sur la métropole lyonnaise - méthodes et résultats', Renault, LET, APDD, Lyons. http://www.ish-lyon.cnrs.fr/labo/let/francais/publications/enligne/rapports/Rapport IMD/rappmeth.pdf

Official Journal of the European Communities (1996) 'Council Directive 96/62 EC, of 27 September 1996 on ambient air quality assessment and management'. En Series, L296/55.

Orfeuil, J.-P. (1984) 'Les budgets énergie-transport: un concept, une pratique, des résultats' Recherche Transports Sécurité, 2, pp. 23-29.

Quin, C., Duprez, F., Bourgis, N. (2001) 'Compte national du transport de voyageurs (1998)'. CERTU, SYSTRA. http://www.certu.fr/transport/cntv.htm.

Routhier, J.-L., Ambrosini, C. (2001) 'Objectives, methods and results of surveys carried out in the field of urban freight transport: an international comparison'. Paper presented et the 9th World Conference on Transport Research, Seoul, July 2001. 
United Nations (1992) 'Report of the United Nations Conference on Environment and Development Chapter 40, Information for Decision making'. Conf.151/26 (Vol. III), Rio de Janeiro, 3-14 June 1992.

United Nations (1996) 'Indicators of Sustainable Development Framework and Methodologies'.

United Nations (2000) 'The Aarhus Convention: an Implementation Guide - UN/ECE Convention on Access on Information, Public Participation in Decision-making, and Access to Justice in Environmental Matters'.

Vivier, J. (1997) 'Coûts des déplacements en Ile-de-France. Eléments pour une politique d'investissement et de tarification'. RATP, Paris.

${ }^{1}$ SUTRA: Sustainable Urban TRAnsportation. $c f . \underline{\text { http://www.ess.co.at/SUTRA/ }}$

${ }^{2}$ Centre d'Etudes sur les Réseaux, les Transports, l'Urbanisme et les constructions publiques - Study Center for Networks, Transport, Urbanism, and Public Works.

${ }^{3}$ The best results are obtained with a correction of this coefficient of 1.3 under the principle that the longer the distance, more the trip tends to near a straight line (Gallez, 1995):

$d c=c f d^{*}\left(1,1+0,3 * e^{(-c f d / 20)}\right)$, with $\mathrm{dc}=0$ for $\mathrm{cfd}=0$ and $\mathrm{dc}=\operatorname{cfd} * 1,1$ for $\mathrm{cfd}>20 \mathrm{~km}$

dc: distance corrected ; cfd: as the crow fly distance

More precision on these tests and on the 1.3 coefficient are to be found in (Nicolas et al., 2001b).

${ }^{4}$ Passenger Car Unit. A light goods vehicle is $1.5 \mathrm{PCU}$, a heavy goods vehicle, $2 \mathrm{PCU}$ and an articulated truck, 3 PCU.

${ }^{5}$ In order to classify households into three equal thirds (low, average and high-income) we used the income per Adult Equivalent Unit (AEU), which makes it possible to take into account the economies of scale which may exist in certain household expenditure and is a more reliable comparison factor for differently sized and structured households than just the total income. The income here is divided by a number of adult equivalents or a number of AEU. The number of AEU is calculated as follows: the first adult has a value of one, any others aged 14 or more have a value of 0.5 and children under the age of 14 have a value of 0.3 (see Hourriez, Ollier, 1997).

${ }^{6}$ There are twice as many old vehicles (more than 5 years old) in low-income families than in high-income families (61\% against $31 \%)$. 